\title{
SSinteza
}

Impact of Internet on Business Activities

\section{GENERALISANJE SADRŽAJA DTK25 KORIŠĆENJEM GIS TEHNOLOGIJE}

\author{
Viktor Marković, Saša T. Bakrač, Radoje D. Banković \\ Vojnogeografski institut, Beograd, Srbija
}

\begin{abstract}
:
U radu je prikazana jedna od mogućih varijanti generisanja sadržaja Digitalne topografke karte razmera 1:25 000 (DTK 25) za potrebe izrade Digitalne topografske karte razmera 1:50 000 (DTK50). Sadržajno rad je baziran na Microsoft Access bazi podataka, dok je generisanje vršeno putem Macroa. Glavni aspekt rada stavljen je na atributskom generisanju, dok geometrijsko generisanje nije razmatrano u većoj meri.
\end{abstract}

\section{Key words:}

Geografski Informacioni sistemi; generisanje, Microsoft Access database, digitalne topografske karte.

\section{UVOD}

Trend istraživanja u oblasti geoprostornih podataka pri izradi geotopografskih materijala u svetu je, prethodnih godina i danas, na automatizaciji proizvodnih procesa. Radi se na definisanju proizvodnog procesa i načinima generalisanja sadržaja iz podataka jedne razmere u drugu sa manje ili više uspeha. Do sada se nije uspelo da potpuno automatizuje proces dobijanja lista karte sitnijeg razmera od podataka prikazanih u krupnijem razmeru. Konkretno, dobijanje Digitalne topografske karte u razmeri 1:50 000 od Digitalne topografske karte u razmeri 1:25 000 (DTK50 od DTK25).

U Vojnogeografskom institutu (VGI) u prethodnih nekoliko godina aktuelna je izrada DTK25. Izrada DTK25 se zasniva na primeni nacionalnih standarda u oblasti prikupljanja, obrade i prezentacije prostornih podataka. U tehnološkom smislu, izrada DTK25 je bazirana na bazi podataka u okviru koje su definisani svi neophodni parametri za generisanje kvalitetnog kartografskog proizvoda odnosno DTK25. Tako definisana baza podataka i u potpunosti usvojene procedure za dobijanje DTK25, predstavljaju osnovni preduslov za generisanje topografskih karata drugih razmera, konkretno DTK50 kao sledeće u razmernom nizu topografskih karata

\section{IZVORI PODATAKA I TEHNIČKI PREDUSLOVI}

Korišćenje DTK25 kao izvora podataka za izradu DTK50 ima i svoje nedostatke koji se ogledaju u većoj količini podataka (veći memorijski zahvat), povećanoj tačnosti podataka (otežava eventualnu naplatu podataka u razmeri 1:50000 jer se u osnovi prodaju 4 baze podataka DTK25 sa većom količinom podataka od podataka koji pripadaju DTK50). Glavni nedostatak bi bio taj što je neophodno izvršiti generalisanje sadržaja DTK25 kako bi se dobila DTK50. Generalisanje je nužno jer za razliku od atributskih podataka koji su prisutni samo u bazi podataka, simbologija i vizuelno prisutni elementi direktno preuzeti sa razmere 1:25000 mogu do te mere da opterete kartu razmere 1:50000 da postane praktično neupotrebljiva sa aspekta štampanog proizvoda [1]. Stoga, neophodna je redukcija i dodatno uobličavanje sadržaja kako bi odštampani list karte kao i vuzualni prikaz na monitoru imali odgovarajuću upotrebnu vrednost.

Tehnološka baza za realizaciju podrazumeva postojanje odgovarajućeg hardvera, softvera i računarske mreže [3]. Neophodan hardver podrazumeva radne stanice visokih performansi i server podataka koji postoji u VGI sa tim što radne stanice po perfomansama nisu odgovarajuće što je u velikoj meri imalo uticaj na sam pristup realiza- 
ciji projekta. Kompletan projekat je realizovan u softveru ArcGIS firme ESRI. Računarska mreža domenskog tipa je već razvijena i operativna je u VGI.

\section{ORGANIZACIJA PODATAKA}

Osnovni preduslov za generalisanje sadržaja je naravno potpuno definisan sadržaj u pripadajućoj bazi podataka (Microsoft Access baza podataka) gde svaki pojedinačni list DTK25 ima jednu pripadajuću bazu podataka. U konkretnom slučaju, nakon usvojenog koncepualnog modela, definisani su hijerarhijski, logički i fizički model podataka i implementacije istih, takođe je definisana i kompletna simbologija za potrebe vizualizacije baze podataka.

Hijerarhijskim modelom je definisan redosled prikaza pojedinačnih vektorskih elemenata organizovanih u bazi podataka kroz objektne klase što određuje način vizualizacije baze podataka odnosno definiše, u konkretnom slučaju, vizuelni identitet same karte [2].

Logički model podataka diktiraju veze između pojedinačnih elemenata vektorskog sadržaja koje su na klasičnoj analognoj karti intuitivno očigledne a koje moraju biti prevedene na jezik baza podataka kako bi korišćeni softver znao kako da tretira pojedinačne pojave. U odnosu na logički model podataka korišćen na razmeri 1:25000, model podataka za kartu u razmeri 1:50000 je morao da pretrpi određene izmene zbog same promene razmere. Veći broj elemenata menja svoj grafički primitiv ili menja sam način prikaza (simbol). Konkretan primer za to je promena tipa grafičkog primitiva za pojedinačne objekte u naselju (stambeni objekti) koji su na DTK25 prikazani kao linijski elementi dok u razmeri DTK50 oni postaju tačkasti elementi. Takođe, karakterističan primer su i urbana područja koja su na karti DTK25 prikazana pojedinačnim objektima (što sama razmera dozvoljava) dok se ista urbana područja na karti DTK50 prikazuju blokovima naselja. Uopšte, broj elemenata koji je pretrpeo određene izmene je veliki. Iz tog razloga neophodno je definisanje logičkog modela podataka i za razmeru 1:50000 sa osloncem na već postojeći model u razmeri 1:25000. Logički model podataka na DTK50 izveden iz logičkog modela podataka DTK25 predstavlja osnov za generalisanje sadržaja DTK25 u svrsi generisanja sadržaja DTK50.

Na slici 1. prikazan je deo logičkog modela podataka na DTK25 [3].

\section{TEMA 5}

ОБЈЕКТИ ЈАВНОГ ЗНАЧАЈАI

\begin{tabular}{|l|c|c|c|c|}
\hline LAYER & TИП & ШИФРА & СИМБОЛ & НАЗИВ \\
\hline 786 & Т & 7861 & $\mathbf{1}$ & Мања фабрика, циглана приказ ван раз. са димњаком \\
\hline
\end{tabular}

TEMA 7

ОБЈЕКТИ ЈАВНОГ ЗНАЧАЈАІІІ

\begin{tabular}{|l|l|l|c|l|}
\hline 791 & $\Pi$ & 7911 & & Фабричка хала, складиште или хангар \\
\hline 793 & $\Pi$ & 7931 & $\boldsymbol{\sim}$ & Фабрички комплекс \\
\hline 894 & $\Pi$ & 8941 & $\boldsymbol{\sim}$ fbr. & (у размери)-фабрика \\
\hline
\end{tabular}

Slika 1. Prikaz dela logičkog modela podataka na DTK25

Fizički model podataka je direktno vezan za logički model podataka odnosno, ova dva modela se međusobno uslovljavaju. Svaka promena u logičkom modelu podataka mora biti sprovedena u fizičkom modelu podataka dok ograničenja (od strane korišćenog softvera i baze podataka) u fizičkom modelu podataka definišu slobodu koju kreator ima u pogledu logičkog modelovanja podataka. $\mathrm{Na}$ ovom modelu su promene u odnosu na DTK25 najveće zbog promene tipa grafičkih primitiva.

Simbologija je realizovana preko stilova (style) s tim što su postojeći stilovi korišćeni na DTK25, na karti DTK50 pretrpeli određene izmene. Ove izmene su, pre svega, uslovljene promenom razmere odnosno promenama dimenzija simbola i tipa simbola. Simbologija je, takođe, uslovljena logičkim modelom podataka. Jer, kao na već pomenutom primeru, ukoliko stambeni objekat menja svoj grafički primitiv iz linije u tačku, takođe, i sam simbol stambenog objekta na razmeri 1:50000 mora biti definisan kao tačka [4]. Prikaz dela kreiranih stilova prikazan je na slici 2.



a)

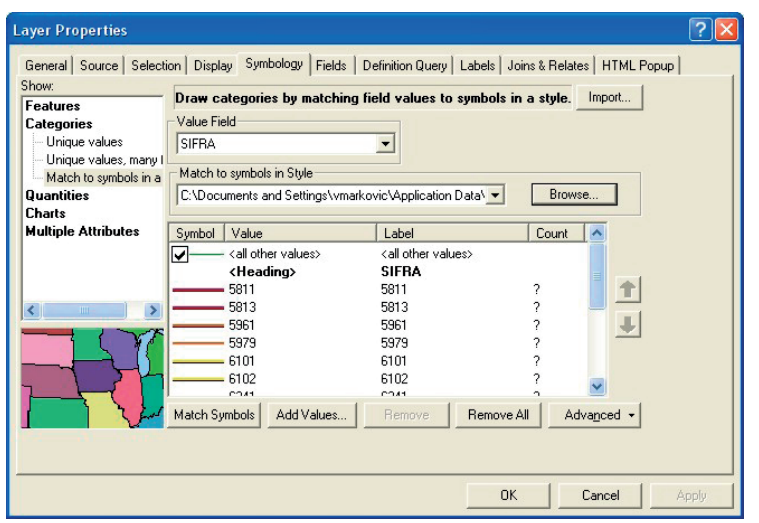

б)

Slika 2. Prikaz dela kreiranih stilova a) prema pripadajućim objektnim klasama i b) prikaz dela samih simbola pohranjenih u stilu

\section{PRISTUP PROBLEMU}

Postoji više varijanti za rešenje ovog problema, međutim, iz razloga hardverskih i softverskih ograničenja kao i stanja trenutnog tehničko tehnološkog razvoja u VGI, izabrana je varijanta u kojoj su listovi DTK 25 pohranjeni na identično mesto na serveru podataka kako bi olakšali nalaženje postojećih baza podataka (jedan list DTK25 ima jednu pripadajuću Microsoft ACESS bazu podataka). To do sada nije bio slučaj jer su se pojedinačne baze podataka 
nalazile u okviru fajl sistema u odgovarajućim organizacionim jedinicama VGI prema tome u kojoj se fazi izrade pojedini listovi DTK25 nalaze. Ovakav pristup, takođe, ubrzava i olakšava rad na generisanju sadržaja DTK50 jer se četiri lista DTK25 nalaze na istom mestu što se u velikoj meri odrazilo na rad u okviru ${ }^{\star}$.mxd projekta [3]. Zbog obima posla projekat se realizuje na uzorku od jednog lista DTK25, što je u skladu sa izabranom varijantom gde se svaki pojedinačni list DTK25 pojedinačno generališe.

\section{GENERALISANJE ELEMENATA SADRŽAJA}

Kartografsko generalisanje sadržaja DTK25 je vršeno prema elemetima sadržaja kako je definisano u postojećem fizičkom modelu podataka.

Koordinatna mreža je konstrisana u državnom sistemu i ona je izvedena od koordinatne mreže korišćena na DTK25. Takođe, u softveru koji se koristi relativno je lako transformisati koordinatnu mrežu u neki drugi sistem.

Komunikacije se gotovo u potpunosti mogu preuzeti sa DTK25 jer su komunikacije element sadržaja koji trpi mali stepen promena prilikom promene razmere sa 1:25000 na 1:50000. Ipak, i na ovom elementu su sprovodene određene izmene. Izvršena je redukcija, u većem obimu, konjskih i pešačkih staza i uklanjanje objekata na i uz komunikacije koji ne ispunjavaju kriterijume prikaza na DTK50. Izvršeno je prešifravanje dela komunikacija a potom je vršeno usklađivanje komunikacija sa ostalim elementima sadržaja DTK50. Po pitanju generalisanja konjskih i pešačkih staza, zbog prirode i značaja ovih elemenata u slabo naseljenim područjima, nije postignut veći stepen automatizacije. Kao rešenje se nametnulo uklanjanje svih pešačih i konjskih staza putem QUERY-ja a potom naknadno ručno vraćanje potrebnih elemenata.

Pri generalisanju objekata na i uz komunikacije koji ne ispunjavaju kriterijume prikaza na DTK50 postignut je veći stepen generalizacije. Rešenje koje je primenjeno podrazumeva pisanje makroa direktno na Microsoft ACESS bazi podataka. Kreirana su dva makroa u kojima se objedinjuju svi uslovi, koje objekti na i uz komunikacije moraju da ispune. Primer funkcionisanja makroa prikazan je na slici 3. Na slici 3. je prikazan deo funcionalnosti makroa na primeru odstranjivanja brojčano slovnog podatka vezanog za vektor komunikacije koji ne ispunjava kriterijume prikaza na DTK50. Makro se izvršava direktno nad bazom podataka tako da se prema zadatom kriterijumu atributska vrednost vektora (na osnovu koje je dobijen brojčano-slovni podatak prikazan na primeru) menja ili briše.

Osnovni nedostatak generalisanja sadržaja na ovakav način prestavlja uniformnosti rezultata QUERY-ja ili makroa. To iz razloga što je veoma teško i vremenski zahtevno precizno definisati i pretočiti u set pisanih pravila sve uslove koje pojedinačni elementi sadržaja moraju da ispune. I pored navedenih nedostataka dosad urađenog, može se konstatovati da postignuti stepen automatizacije generalizacije sadržaja na komunikacijama varira jer zavisi od stepena opterećenosti sadržajem kao i karaktera kartiranog područja. Uslovno može se reći da je postignut stepen automatizacije generalizacije sadržaja komunikacija prilikom prelaska sa razmere 1:25000 na 1:50000 od 40-50\%.

Naselja kao element sadržaja DTK25 koji se generališe za potrebe prikaza na DTK50 je pretrpeo najveći obim promena. To iz razloga što je dosadašnji način prikaza bio pojedinačnim objektima (stambeni objekti-kućice) a što je imalo svojih prednosti u smislu boljeg prikaza karaktera naselja. Međutim, nedostaci ovakvog načina prikaza se ogledaju u količini vremena potrebnog za uzradu i angažovanju ljudstva.
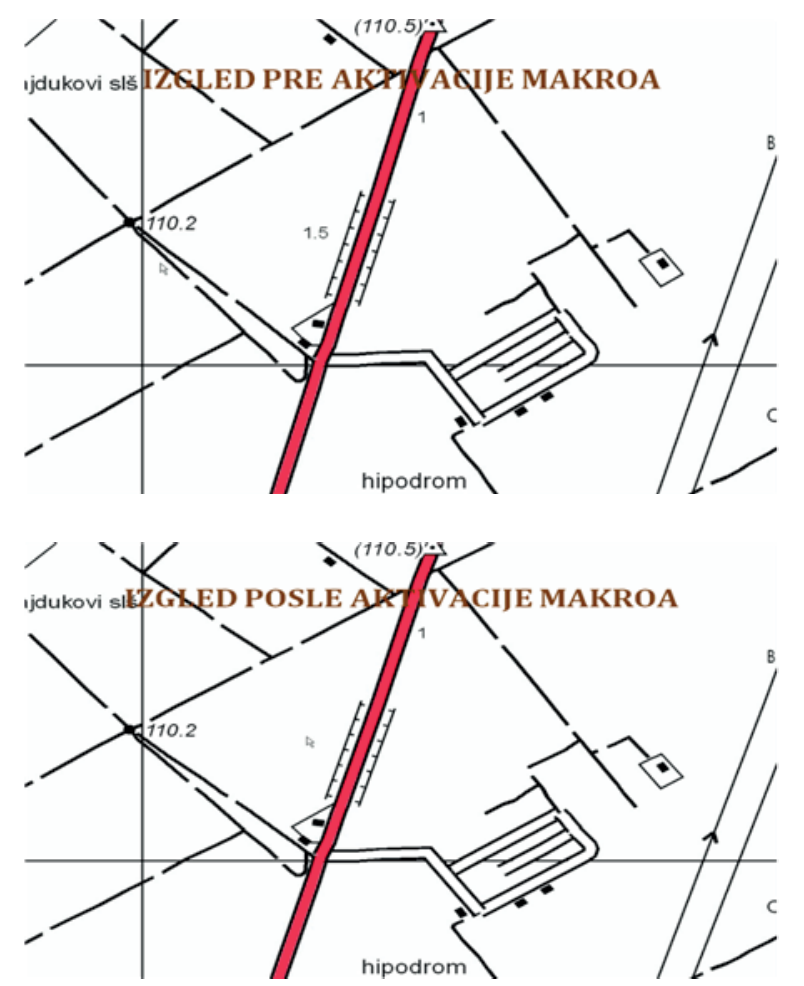

Slika 3. Prikaz dela funcionalnosti makroa pre i posle aktivacije

Kako bi ublažili uticaj nedostataka prikaza naselja pojedinačnim objektima na DTK25, pribeglo se prikazu urbanih područja blokovima naselja (poligonima). Ovo rešenje je, takođe, primenjeno na većini karata stranih zemalja razmera 1:50000 [4]. Prikaz naselja poligonima ima određene prednosti koje se, osim toga što je svojevrstan standard, ogleda u skraćenom vremenu za izradu i manjem broju angažovanog ljudstva. Takođe, prisutni su i nedostaci koji se ogledaju u tačnosti i nemogućnosti prikaza karaktera naselja. Obzirom da se naselja na razmeri 1:50000 prvi put prikazuju blokovima, još uvek se u fazi iznalaženja optimalnog rešenja za prevođenje grupa pojedinačnih kućica u poligone naselja, odnosno da se prikaž set pravila u pisanom obliku. Iz razloga postojanja velikog broja pravila koje nameće kartografija, nije se uspelo da u većoj meri automatizuje ovaj proces. Međutim, upotreba pojedinačnih objekata prikazanih na DTK25 je moguća i umnogome ubrzava rad prilikom generisanja sadržaja DTK50. Veći stepen automatizacije je postignut prilikom generalisanja pojedinačnih objekata od javnog značaja $i$ to je, takođe, urađeno preko makroa. Na primer, neki od uslova koji moraju biti ispunjeni prilikom prikaza na DTK50 su: zgrade prikazane u razmeri kao i objekti jav- 
nog značaja moraju imati površinu veću od $600 \mathrm{~m}^{2}$, soliteri prikazani u razmeri, ukoliko nemaju površinu veću od $2000 \mathrm{~m}^{2}$ prelaze u vanrazmerne objekte (vrši se promena identifikatora u bazi podataka odnosno menja se pripadajući simbol) i drugi. Izgled naselja predstavljenog pojedinačnim objektima i blokovima predstavljen je na slici 4. .



a)

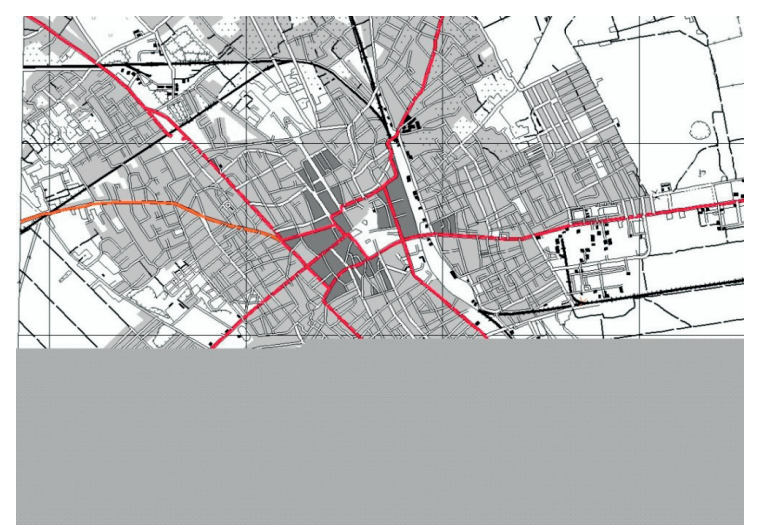

b)

Slika 4. Prikaz naselja pojedinačnim objektima na DTK25 (a), prikaz naselja blokovima na DTK50 (b)

Hidrografija je u potpunosti preuzeta sa DTK25 s tim što identična pravila generalisanja koja su primenjena na komunikacijama važe i na hidrografiji (uz poštovanje specifičnosti hidrografije kao elementa prikaza odnosno dodatnih uslova koje hidrografija mora da ispuni). To znači da se uz pomoć makroa postigao identičan stepen automatizacije.

Kompletan sadržaj reljefa je preuzet sa DTK25 a generalisanje koje se primenilo odnosilo se na pomoćne izohipse. Generalisanje je izvedeno preko QUERY-ja jer neuniforman raspored pomoćnih izohipsi ne dozvoljava kreiranje makroa. Priroda pomoćnih izohipsi je takva da se one postavljaju samo tamo gde za njima ima potrebe $\mathrm{u}$ iskazivanju visinske predstave terena što znači da je u pitanju delimično subjektiva procena kartografa koju nije moguće pretočiti u set pisanih pravila a koja su neophodna za kreiranje makroa. Uz pomoć QUERY-ja se postigao određen stepen generalizacije, međutim, kako bi se održao visok kvalitet visinske predstave terena, neophodna je ručna dorada odnosno ručno generalisanje.

Međusobno usklađivanje elemenata sadržaja nakon poluautomatskog generalisanja na DTK50 se vrši uglanom manualno, međutim i tu je postignut određen stepen automatizacije uz korišćenje prostornih upita odnosno selekcija [3]. Prikaz dela DTK50 generisane na osnovu DTK25 je prikazan na slici 5.

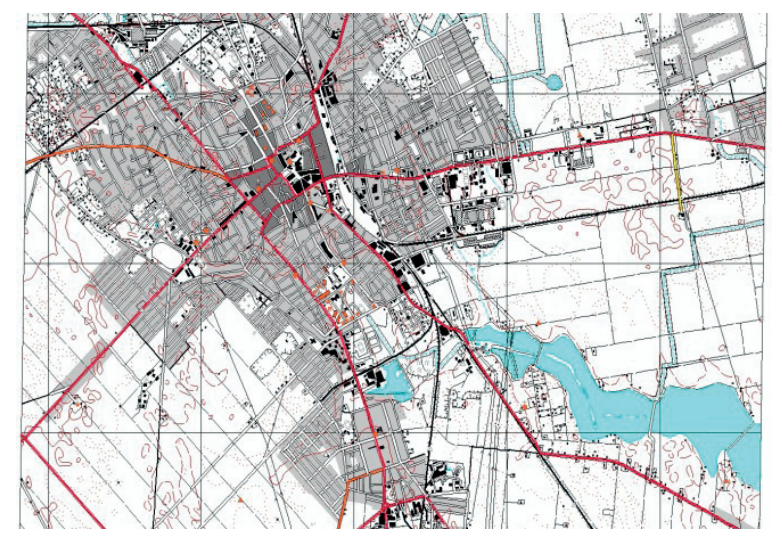

Slika 5. Prikaz dela DTK50 generisane na osnovu DTK25

\section{ZAKLJUČAK}

Ovaj projekat je pokazao da je moguće upotrebiti vektorske podatke (podržane bazom podataka) prikupljene u razmeri 1:25000 (DTK25) za generisanje DTK50. Podatke je moguće u potpunosti preuzeti sa DTK25. Stepen automatizacije procesa generalisanja tako preuzetih podataka zavisi od tipa prikazanih podataka.

Jedan od osnovnih problema sa kojim se može suočiti jeste nedovoljno razrađen model podataka. On jeste odgovarajući za DTK25 ali zahteva ozbiljnu doradu kako bi mogao da se koristi i u drugim razmerama, na primer DTK50, što je vremenski veoma zahtevan i osetljiv posao. To znači da model podataka koji se koristi za DTK25, kao početnu razmeru za koju se prikupljaju podaci, mora u sebi da sadrži i modele podataka za sve ostale razmere koje će se izvoditi iz DTK25.

Eventualni propusti u modelu podataka, usvojenom i na upotrebi, se naknadno teško i skupo ispravljaju. Zato je neophodno defiinsati model podataka [3] za sve razmere koje će se izvoditi iz DTK25 (i logički i fizički) kako bi mogao da obezbedi prihvat podataka i u razmeri 1:25000 i 1:50000.

Takođe, veliki problem predstavlja korišćenje Microsoft ACESS baze podataka koja se pokazala kao neadekvatna za prihvat velike količine prostornih podataka. U toku rada na projektu izvršeno je testiranje na SQL Express bazi podataka koja se pokazala znatno boljom, tako da će dalji rad biti usmeren u tom pravcu.

\section{LITERATURA}

[1] Banković, R., Borisov, M., Drobnjak, S., Modelovanje procesa nad topografskim podacima, Glasnik Srpskog geografskog društva, Baograd, 2010, str. 207-218.

[2] C. Jones, Geographical Information Systems and Computer Cartography, Addison Wesley Longman, 1997, pp 1-319.

[3] Marković, V., Opšti principi logičkog modelovanja strukture podataka za potrebe izrade digitalne topografske karte razmera 1:25000, Zbornik radova br. 13, Beograd, 2009, str. 17-25, 
[4] M. J. Egenhofer, J. R. Herring, Categorizing binary topological relationships between regions, lines and points in geographical database, Technical Report, Department of Surveying Engineering, University of Maine, Orono, 1991.

[5] Wolfgang Kresse, David M. Danko, Handbook of Geographic Information, Springler -Verlag, Berlin Heidelberg, 2012, pp 30-1130.

\section{Abstract:}

This paper shows one of possible variants generating content of Digital Topographical map scale of 1:25 000 (DTK 25) for the making of digital topographic maps in scale 1:50 000 (DTK50). In terms of content paper is based on a Microsoft Access database, while generating was done by Macroom. The main aspect of the work was put on the attribute generating, while the geometric generating is not contemplated to a greater extent.

\section{Key words:}

Geographical Information Systems, generating, Microsoft Access database, Digital Topographical maps. 